\title{
Suppression of skin tumorigenesis in CD109-deficient mice
}

\author{
Masaki Sunagawa1,2, Shinji Mii,1,3, Atsushi Enomoto1, Takuya Kato ${ }^{4}$, Yoshiki \\ Murakumo ${ }^{5}$, Yukihiro Shiraki', Naoya Asai ${ }^{3}$, Masato Asai ${ }^{1}$, Masato Nagino ${ }^{2}$, \\ Masahide Takahashi ${ }^{1,3}$ \\ ${ }^{1}$ Department of Pathology, Nagoya University Graduate School of Medicine, Nagoya, Japan \\ ${ }^{2}$ Division of Surgical Oncology, Department of Surgery, Nagoya University Graduate School of Medicine, Nagoya, Japan \\ ${ }^{3}$ Division of Molecular Pathology, Center for Neurological Disease and Cancer, Nagoya University Graduate School of Medicine, \\ Nagoya, Japan \\ ${ }^{4}$ Tumour Cell Biology Laboratory, The Francis Crick Institute, Lincoln's Inn Fields Laboratories, London, United Kingdom \\ ${ }^{5}$ Department of Pathology, Kitasato University School of Medicine, Sagamihara, Japan \\ Correspondence to: Masahide Takahashi, email: mtakaha@med.nagoya-u.ac.jp \\ Keywords: skin carcinogenesis, CD109, TGF- $\beta$, p21, Nrf2
}

Received: May 16, $2016 \quad$ Accepted: October 02, 2016

Published: October 14, 2016

\section{ABSTRACT}

CD109 is a glycosylphosphatidylinositol-anchored glycoprotein that is highly expressed in several types of human cancers, particularly squamous cell carcinomas. We previously reported that CD109-deficient mice exhibit epidermal hyperplasia and chronic skin inflammation. Although we found that CD109 regulates differentiation of keratinocytes in vivo, the function of CD109 in tumorigenesis remains unknown. In this study, we investigated the role of CD109 in skin tumorigenesis using a twostage carcinogenesis model in CD109-deficient mice with chronic skin inflammation. Immunohistochemical analysis revealed a higher level of TGF- $\beta$ protein expression in the dermis of CD109-deficient mice than in that of wild-type mice. Additionally, immunofluorescence analysis showed that Smad2 phosphorylation and Nrf2 expression were enhanced in primary keratinocytes from CD109-deficient mice compared with in those from wild-type mice. Although no significant difference was found in conversion rates from papilloma to carcinoma between wild-type and CD109deficient mice in the carcinogenesis model, we observed fewer and smaller papillomas in CD109-deficient mice than in wild-type mice. Apoptosis and DNA damage marker levels were significantly reduced in CD109-deficient skin compared with in wildtype skin at $24 \mathrm{~h}$ after 7, 12-dimethylbenz (a) anthracene treatment. Furthermore, mutation-specific PCR revealed that the mutation frequency of the H-ras gene was less in CD109-deficient skin than in wild-type skin in this model. These results suggest that CD109 deficiency suppresses skin tumorigenesis by enhancing TGF- $\beta /$ Smad/Nrf2 pathway activity and decreasing the mutation frequency of the H-ras gene.

\section{INTRODUCTION}

Squamous cell carcinoma (SCC) is the second most common skin cancer, with a rising incidence over the past three decades. Approximately 700,000 new cases of cutaneous SCC are diagnosed annually in the United States of America [1]. Although skin SCCs have a generally favorable prognosis, approximately $1.5 \%-2 \%$ of patients die from the disease $[1,2]$. Additionally, skin SCCs are most commonly found in sun-exposed areas of the body, such as the head and neck, where surgery may be disfiguring [2]. Several risk factors are associated with skin SCC, including exposure to ultraviolet light, arsenic, or tobacco; human papilloma virus infection; and exposure to chemicals, including 7, 12-dimethylbenz $(\alpha)$ anthracene (DMBA) [3, 4].

CD109, a glycosylphosphatidylinositol-anchored glycoprotein, is a member of the $\alpha_{2}$-macroglobulin/C3, C4, C5 family of thioester-containing proteins [5-8]. CD109 is a cell surface protein expressed on CD34- 
positive bone marrow mononuclear cells, activated $\mathrm{T}$ lymphoblasts, activated platelets, endothelial cells and mesenchymal stem cell subsets [5, 9-11]. We previously reported high levels of CD109 expression in various tumor cell lines and tumor tissues including SCCs of the lung, esophagus, uterus and oral cavity; malignant melanoma of the skin; and urothelial carcinoma of the urinary bladder [12-20]. CD109 expression was significantly higher in well-differentiated SCCs of the oral cavity than in normal oral mucosa and moderately or poorly differentiated SCCs $[17,20]$. These findings suggest that CD109 is associated with tumor development, especially in SCCs. CD109 also functions as a negative regulator of transforming growth factor (TGF)- $\beta$ signaling in human keratinocytes. CD109 inhibits receptor-regulated Smad (R-Smad) activation, probably by direct modulation of TGF- $\beta$ receptor activity [21-24]. CD109 is also reportedly associated with human psoriasis $[25,26]$, and CD109-deficient mice have been shown to exhibit inflammatory cell infiltration of the dermis [27]. The majority of infiltrating cells were found to be T lymphocytes, which were identified as CD3positive by immunohistochemistry.

Signaling via the TGF- $\beta$ receptor system induces a wide range of biological responses including cell proliferation, differentiation, migration and apoptosis; tissue remodeling; and immune response [28, 29]. Ligand-mediated assembly of TGF- $\beta$ receptor (TGFBR) I and TGFBRII initiates an intracellular phosphorylation cascade. Activated TGFBRII transphosphorylates TGFBRI, which subsequently phosphorylates R-Smads such as $\operatorname{Smad} 2 / 3$, which in turn enables the R-Smads to bind a common mediator, Smad4. R-Smad/Smad4 complexes accumulate in the nucleus where they act as transcription factors for target genes [28]. TGF- $\beta$ functions as a tumor suppressor in precancerous cells, but as an enhancer of invasion and metastasis in more advanced carcinoma cells $[29,30]$. In addition, a recent report showed that TGF- $\beta$ activates $\mathrm{p} 21^{\mathrm{WAF} 1 / \mathrm{CIP} 1}(\mathrm{p} 21)$ and nuclear factor erythroid 2-related factor 2 (Nrf2), thereby enhancing glutathione metabolism and antioxidant response in SCCs in vivo [31]. p21 prevents cell cycle progression [31] and activates the Nrf2 transcription factor [32]. Nrf2-deficient mice were found to be more susceptible to skin tumorigenesis [33] and Nrf2 activation protected keratinocytes in the early phase of skin tumorigenesis [34].

We used one of the most frequently used carcinogenesis models, in which topical application of DMBA, a polycyclic aromatic hydrocarbon that induces DNA alteration, was followed by the topical application of tetradecanoyl-phorbol acetate (TPA), which stimulates inflammation and epidermal proliferation [35]. In a previous study using this model, H-ras ${ }^{(Q 61 L)}$ mutation, shown to be associated with H-ras gene amplification, was detected in papillomas as well as carcinomas [36]. This observation suggests that H-ras is an early driver in the carcinogenesis model $[35,36]$. In this study, we investigated the role of CD109 in the development of SCC using CD109-deficient mice.

\section{RESULTS}

\section{CD109 deficiency enhances TGF- $\beta$ signaling in mouse skin}

Although CD109 is reported to function as a negative regulator of TGF- $\beta$ signaling in human keratinocytes [22-25], we previously observed no effect of CD109 deficiency on the TGF- $\beta$ signaling pathway in the mouse epidermis in vivo [27]. In this study, we first examined TGF- $\beta /$ Smad signaling in the whole skin of $C D 109^{+/+}$ and $C D 109^{-/-}$mice. Immunoblot analysis using lysates prepared from the whole skin of $C D 109^{+/+}$and $C D 109^{-/-}$ mice showed that the TGF- $\beta /$ Smad signaling pathway was activated in $\mathrm{CD}_{109^{-/-}}$skin but not in $\mathrm{CD}_{109^{+/+}}$skin (Figure 1A). Immunohistochemical analysis revealed a higher level of TGF- $\beta 1$ protein in the dermis of $C D 109^{-/-}$ mice than in that of $C D 109^{+/+}$mice (Figure 1B). TGF- $\beta 1$ was undetectable in the epidermis of both $C D 109^{+/+}$and $C D 109^{-/-}$mice; the epidermis-dermis junction was more strongly stained with anti-TGF- $\beta 1$ antibody than the deeper dermis in $C D 109^{-/-}$skin. Conversely, no apparent differences in TGFBRI or TGFBRII expression were observed immunohistochemically between $\mathrm{CD} 109^{+/+}$and $C D 109^{-/-}$skin (Supplementary Figure S1A).

We next investigated the expression of inflammation-related genes, including $T g f b l$, in the skin of $C D 109^{+/+}$and $C D 109^{-/-}$mice. We used Q-PCR analysis to determine the mRNA expression levels of various cytokines (Figure 1C). There were no significant differences in mRNA levels of several cytokines, including interleukins and interferon- $\gamma$, between $C D 109^{+/+}$and $C D 109^{-/-}$mice; however $T g f b 1, C s f 2$, and Tnfa mRNA expression levels were significantly higher in $C D 109^{-/-}$ mice than in $C D 109^{+/+}$mice $(P<0.05)$. In addition to the increase observed in TGF- $\beta 1$ protein levels (Figure 1B), the protein levels of TNF- $\alpha$ and GM-CSF (encoded by $C s f 2$ ) were higher in the skin of $C D 109^{-/-}$mice than in that of $\mathrm{CD} 109^{+/+}$mice (Supplementary Figure S1B). GMCSF is produced by various cells, including macrophages and fibroblasts; it activates macrophages and induces TNF- $\alpha$ production [37]. Immunohistochemical analysis using anti-F4/80 antibody revealed more macrophages infiltrating the dermis of $C D 109^{-/-}$mice than that of $\mathrm{CD}_{109^{+/+}}$mice (Figure 1D). These findings indicate that CD109 deficiency not only enhances TGF- $\beta$ signaling but also induces macrophage infiltration in mouse skin.

To clarify the relationship between the increase in TGF- $\beta 1$ levels and the increase in the number of macrophages infiltrating the dermis in CD109-deficient mice, we performed macrophage depletion experiments using clodronate liposomes. Macrophage depletion 


\section{Whole skin}

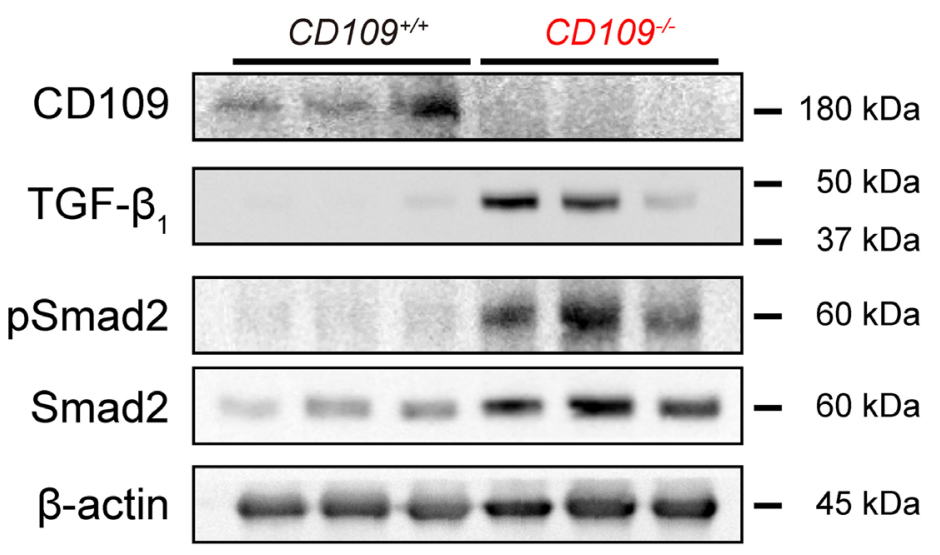

B

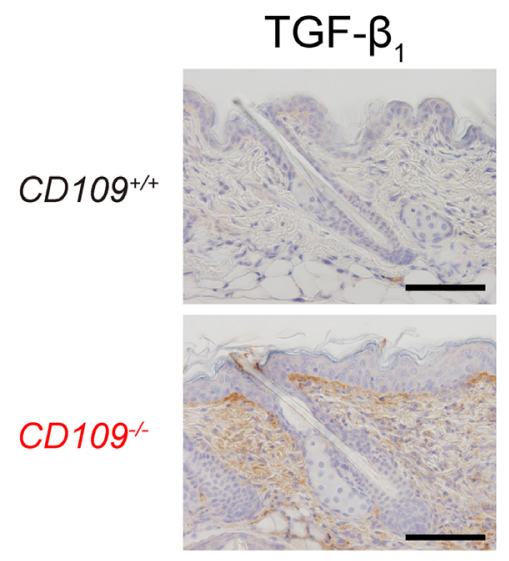

\section{C}

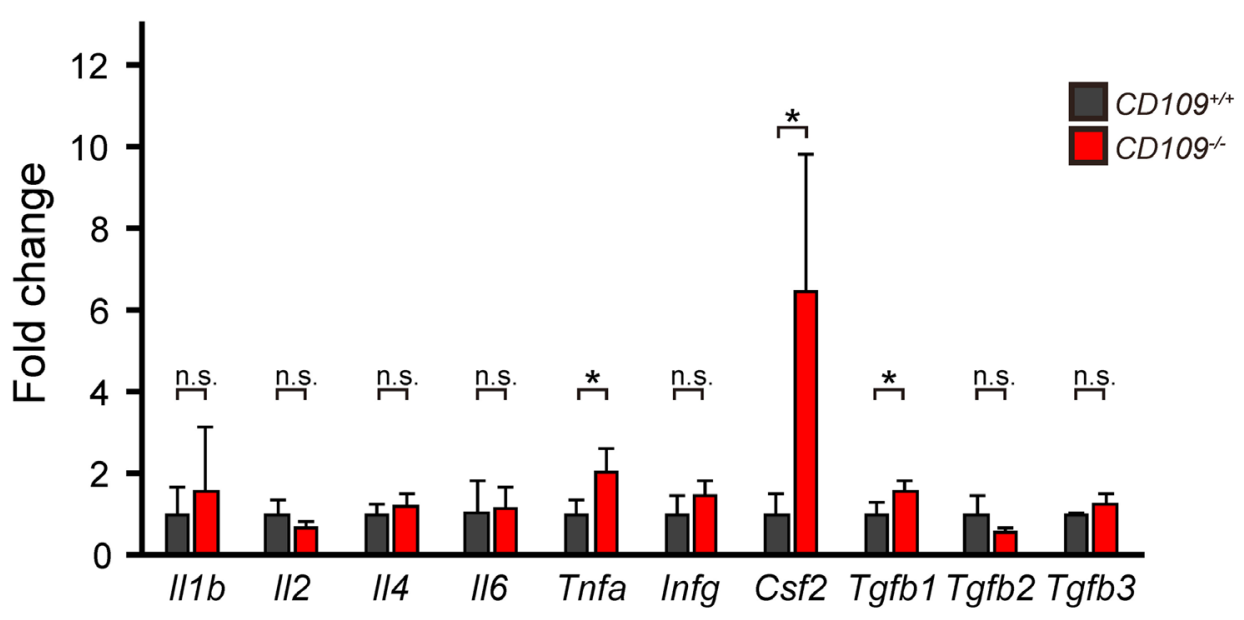

D
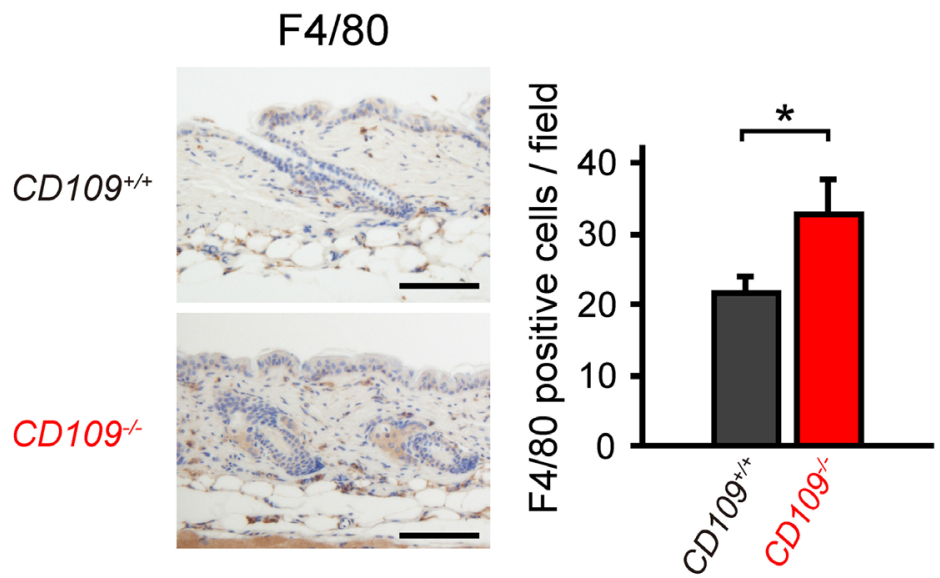

Figure 1: CD109 deficiency enhanced TGF- $\beta$ signaling and induced macrophage infiltration in mouse skin. A. Immunoblot analysis of whole-skin lysates from 6-week-old $\mathrm{CD} 109^{+/ /}$and $C D 109^{-/-}$mice using antibodies against CD109, TGF- $\beta 1$, pSmad2, and Smad2 ( $\mathrm{n}=3$ per group). Expression of $\beta$-actin is shown as a loading control. B. Immunohistochemical analysis of TGF- $\beta 1$ expression in the dermis of 6-week-old $\mathrm{CD} 109^{-/}$and $\mathrm{CD} 109^{+/+}$mice. Scale bars, $100 \mu \mathrm{m}$. C. Expression levels of mRNAs encoding the indicated cytokines in the skin of 6-week-old $\mathrm{CD}_{109^{+/ /}}$and $\mathrm{CD}_{109^{-/}}$mice, determined by quantitative PCR ( $\mathrm{n}=4$ per group). D. Immunohistochemical analysis showing F4/80-positive cells (macrophages) in the skin of 6-week-old $C D 109^{+/+}$and $C D 109^{-/}$mice. Right, quantification of F4/80-positive cells in the dermis. Scale bars, $100 \mu \mathrm{m}$; n.s., not significant; ${ }^{*} P<0.05$. 
by subcutaneous injection of clodronate lipsomes was confirmed by immunohistochemical analysis with anti-F4/80 antibody (Supplementary Figure S2A). There were no significant differences in the number of F4/80positive cells between clodronate-treated $C D 109^{+/+}$and $C D 109^{-/-}$skin (Supplementary Figure S2A). Additionally, no significant differences were observed in mRNA levels of Tgfb1, Tnfa and Csf2 between clodronate-treated $C D 109^{+/+}$and $C D 109^{-/-}$skin (Supplementary Figure S2B). These findings suggest that TGF- $\beta 1$ was at least partly secreted from the macrophages that infiltrated the dermis in CD109-deficient mice.

\section{Roles of CD109 in DMBA-induced cytotoxicity in primary mouse keratinocytes}

A recent study demonstrated that TGF- $\beta$ enhanced glutathione metabolism and antioxidant response in SCCs via activation of p21 and Nrf2 [31]. To examine the effect of CD109 deficiency on the antioxidant response in keratinocytes, we assessed proliferation rate and viability of primary mouse keratinocytes by WST-1 assay. The proliferation rate of $C D 109^{+/+}$keratinocytes was significantly higher than that of $C D 109^{-/-}$keratinocytes in the defined medium without TGF- $\beta(P<0.05$; Figure $2 \mathrm{~A})$. This finding is consistent with a previous study that showed that CD109-overexpressing HEK293 cells grew faster than control cells [17]. Interestingly, the viability of $C D 109^{-/-}$keratinocytes was significantly higher than that of $C D 109^{+/+}$keratinocytes in the presence of DMBA or cisplatin (CDDP), regardless of TGF- $\beta 1$ pretreatment $(P$ $<0.01$; Figure 2B, $P<0.05$; Supplementary Figure S3A). No significant differences were observed in cell viability in the presence of DMBA between TGF- $\beta 1$-pretreated and PBS-pretreated $C D 109^{+/+}$keratinocytes (Figure 2B, Supplementary Figure S3B); however, the viability of $C D 109^{-/-}$keratinocytes in the presence of DMBA was significantly higher after TGF- $\beta 1$-pretreatment than after PBS-pretreatment $(P<0.01$; Figure $2 \mathrm{~B}, P<0.05$; Supplementary Figure S3C). Additionally, the viability of $C D 109^{-/}$keratinocytes in the presence of DMBA was decreased by p21 knockdown using siRNA targeting p21 (Supplementary Figure S3D and S3E). Moreover, the viability of $C D 109^{-/-}$keratinocytes pretreated with TGFBRI inhibitor was significantly lower than that of PBS-pretreated $C D 109^{-/-}$keratinocytes in the presence of DMBA $(P<0.01$; Supplementary Figure S3C). This finding suggests that resistance of TGF- $\beta$ to DMBA- or CDDP-induced cytotoxicity was enhanced in $C D 109^{-/-}$ keratinocytes compared with in $C D 109^{+/+}$keratinocytes. Immunofluorescence analysis showed that Smad2 phosphorylation was elevated in $\mathrm{CD} 109^{-/-}$keratinocytes compared with in $C D 109^{+/+}$keratinocytes (Figure 2C).

To investigate the mechanism underlying the increased viability of $\mathrm{CD}_{109^{-/-}}$keratinocytes in the presence of DMBA or CDDP, we analyzed the expression levels of p21 and Nrf2, mediators of the antioxidant response, which are known to protect against toxic effects of DMBA and CDDP [31, 38]. Immunofluorescence analysis showed that nuclear localization of p21 and Nrf2 was significantly increased in $C D 109^{-/}$keratinocytes compared with in $C D 109^{+/+}$keratinocytes $(P<0.01$; Figure 2D, 2E). We also examined Nrf2 expression levels in vivo using immunohistochemistry, and observed higher Nrf2 expression in the epidermis of 6-week-old $\mathrm{CD}_{109^{-/-}}$mice than it that of $\mathrm{CD} 109^{+/+}$mice (Figure $2 \mathrm{~F}$ ). In addition, we evaluated detoxification enzymes, some of which are regulated by $\mathrm{Nrf} 2$ in keratinocytes [39]. There were no significant differences in the expression levels of detoxification enzymes that are reportedly not regulated by Nrf2 between $C D 109^{+/+}$and $C D 109^{-/-}$skins (Supplementary Figure S4A); however, the mRNA and protein levels of several detoxification enzymes that are reportedly regulated by $\mathrm{Nrf2}[34$, 40] were elevated in $C D 109^{-/-}$skin compared with in $C D 109^{+/+}$skin (Supplementary Figure S4B and S4C). Moreover, microarray analysis revealed that Akr1c19, one of the Nrf2-related detoxification enzymes [40], was downregulated in $C D 109^{+/+}$skin and upregulated in $C D 109^{-/-}$skin after DMBA treatment, as compared with untreated skin (Supplementary Tables S2 and S3). These findings suggest that CD109 deficiency increases resistance to DMBA- or CDDP-induced cytotoxicity in primary mouse keratinocytes via the TGF- $\beta / \mathrm{p} 21 / \mathrm{Nrf} 2$ pathway.

\section{CD109 deficiency suppresses DMBA/TPA- induced skin tumorigenesis}

To examine the role of CD109 in skin tumorigenesis in vivo, we used a two-stage carcinogenesis model in CD109-deficient mice with chronic skin inflammation. A schematic diagram of the two-stage carcinogenesis protocol using DMBA and TPA is shown in Figure 3A. Macroscopically, we found fewer and smaller skin tumors in $C D 109^{-/-}$mice compared with in $C D 109^{+/+}$mice in this model (Figure 3B). The tumors were diagnosed histologically as papillomas at 17 weeks after DMBA initiation. There were no apparent histological differences between $C D 109^{+/+}$and $C D 109^{-/-}$papillomas, except for the tumor size (Figure 3C, Supplementary Figure S5A). Skin tumors were counted and measured once a week to quantify the tumor number and size. Skin tumors tended to appear later and tumor number per mouse was significantly lower in $C D 109^{-/-}$mice than in $C D 109^{+/+}$ mice $(P<0.05$; Figure 3D). Total tumor volume per mouse was also significantly lower in $C D 109^{-1-}$ mice than in $C D 109^{+/+}$mice $(P<0.05$; Figure $3 \mathrm{E})$.

Epidermal basal cell proliferation and keratinocyte apoptosis in papillomas were assessed immunohistochemically by staining with anti-Ki-67 and anti-cleaved caspase- 3 antibodies, respectively. The 
A

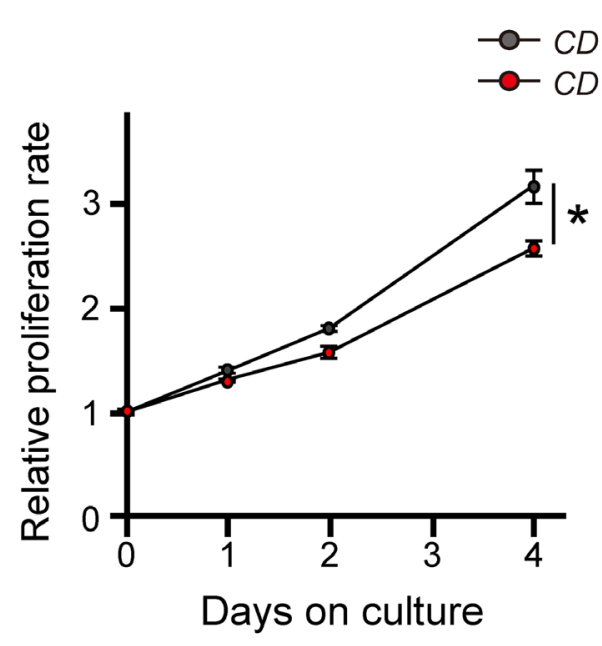

C

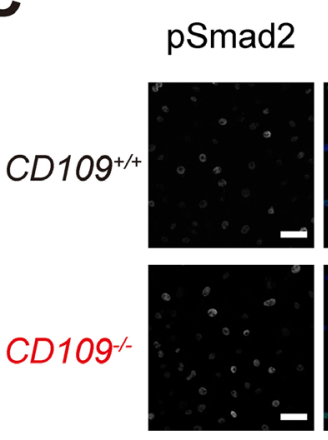

pSmad2I
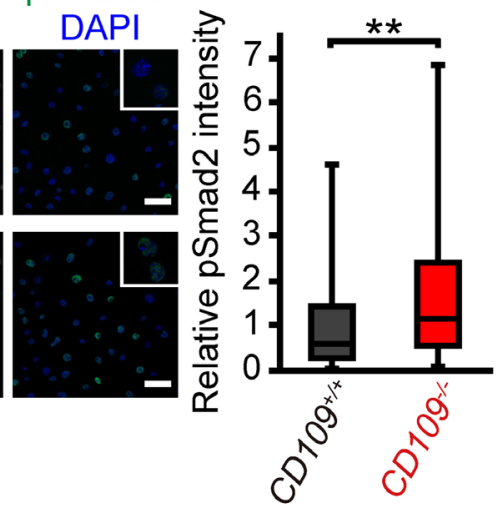

E

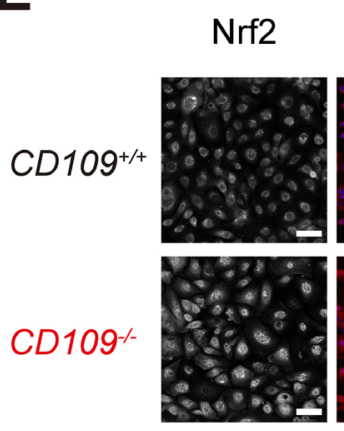

Nrf2/

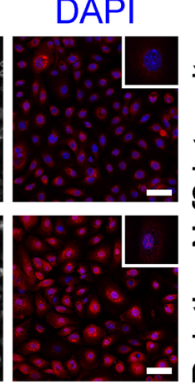

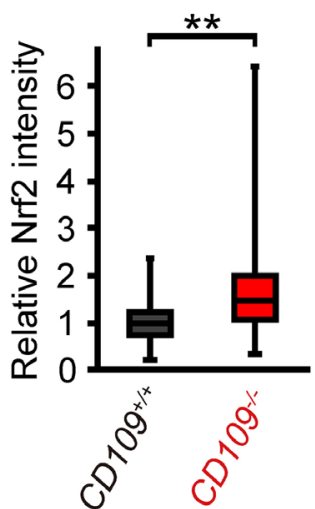
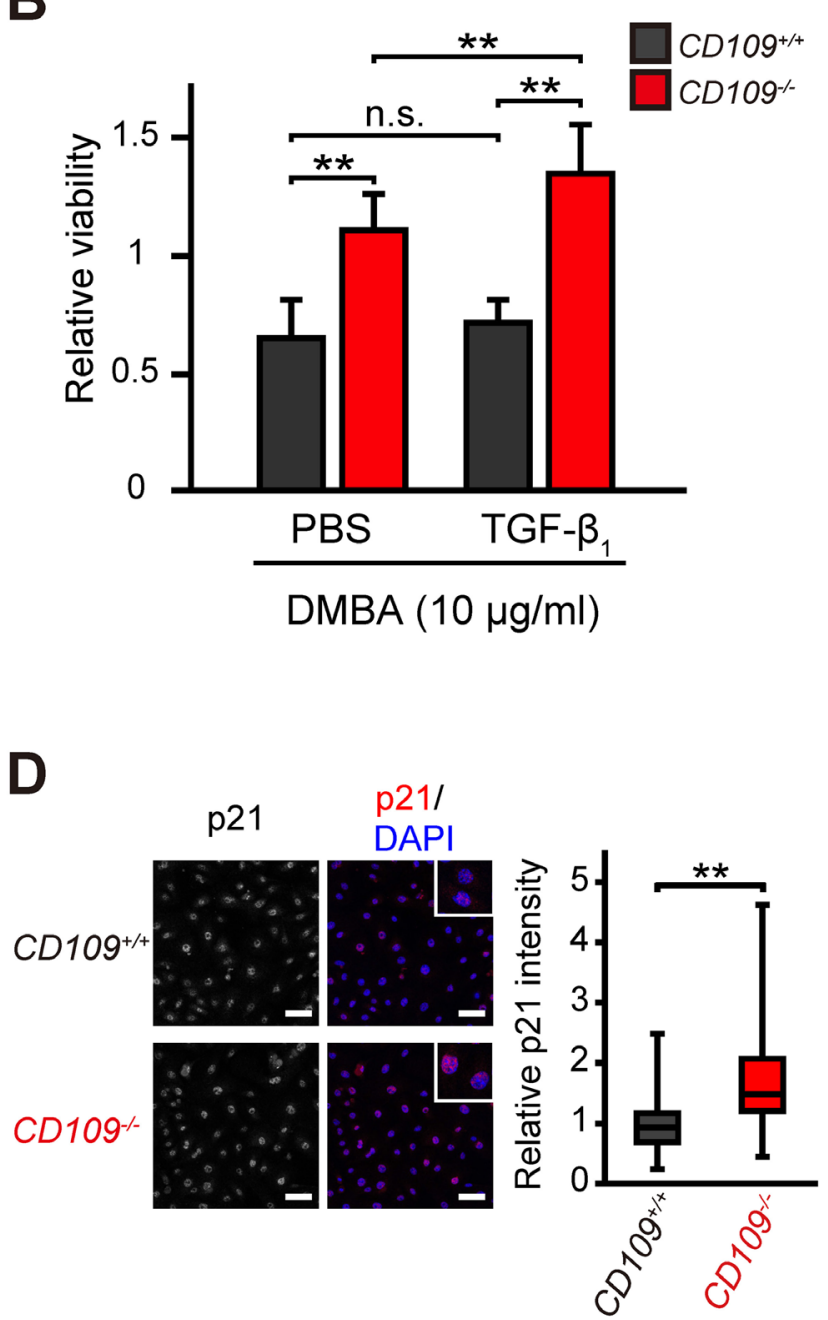

$\mathbf{F}$

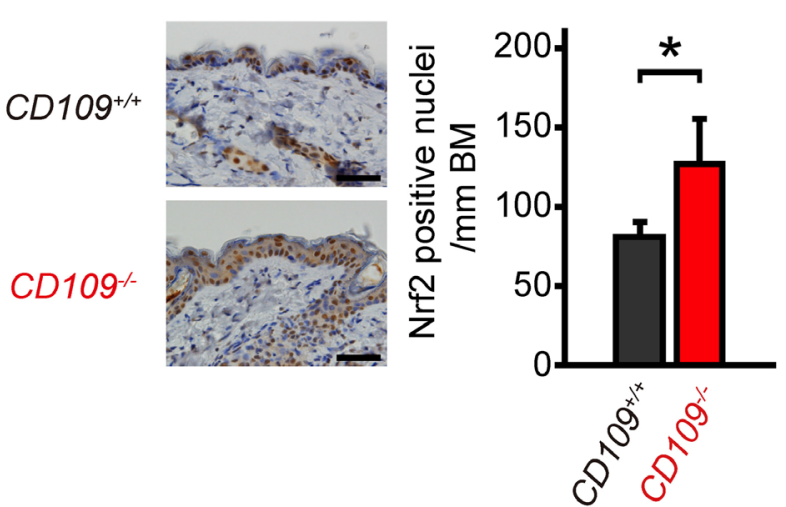

Figure 2: Cellular characteristics of primary mouse keratinocytes. A. $C D 109^{+/+}$and $C D 109^{-/}$keratinocyte proliferation rates, measured by WST-1 assay (n $=6$ per group). B. Viability of $C D 109^{+/+}$and $C D 109^{-/-}$keratinocytes in the presence of DMBA $(10 \mu \mathrm{g} / \mathrm{ml})$, measured by WST-1 assay ( $\mathrm{n}=3$ per group). Cells were pretreated with PBS only (control) or TGF- $\beta 1$ ( $10 \mathrm{ng} / \mathrm{ml}$ ) for $24 \mathrm{~h}$ before incubation with DMBA. C-E. Fluorescence immunostaining for pSmad2 (C), p21 (D), and $\mathrm{Nrf2}(\mathrm{E})$ in $C D 109^{+/+}$and $\mathrm{CD}_{109^{-/}}$keratinocytes $(\mathrm{n}=90 \mathrm{per}$ group). Insets show higher magnification of positive cells. Scale bars, $50 \mu \mathrm{m}$. Right graphs, quantification of immunofluorescence intensity. F. Immunohistochemical staining for $\mathrm{Nrf2}$ in the skin of 6-week-old $\mathrm{CD}_{109^{+/+}}$and $\mathrm{CD}_{109^{-/}}$mice (left panels). The number of Nrf2positive cells in epidermis was counted per $\mathrm{mm}$ of basement membrane (BM) (right graph; $\mathrm{n}=4$ per group). DMBA, 7, 12-dimethylbenz $(\alpha)$ anthracene; $* P<0.05 ; * * P<0.01$. 
A

DMBA TPA

(Initiation) (Promotion)

No treatment

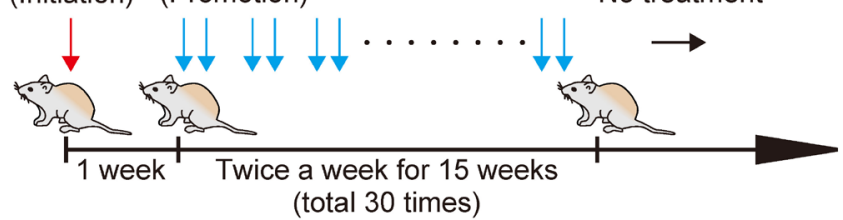

B

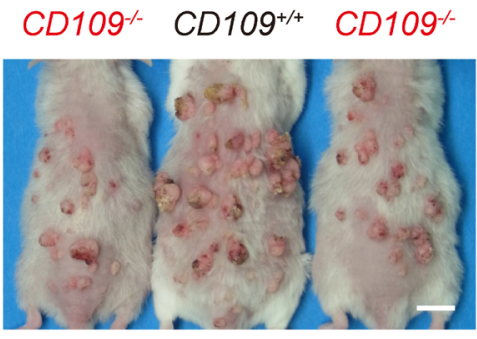

16 weeks after DMBA initiation

C
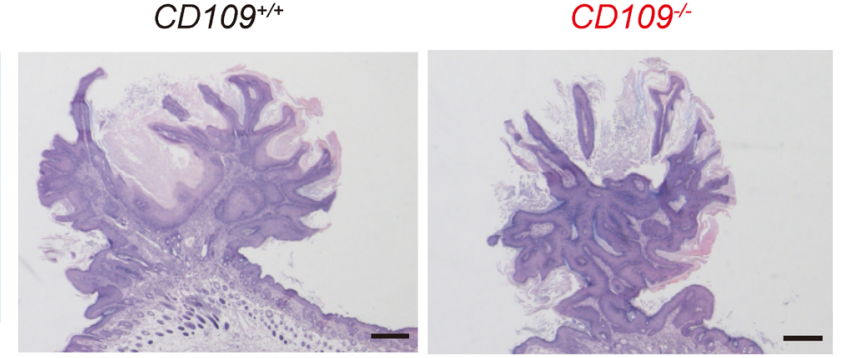

D
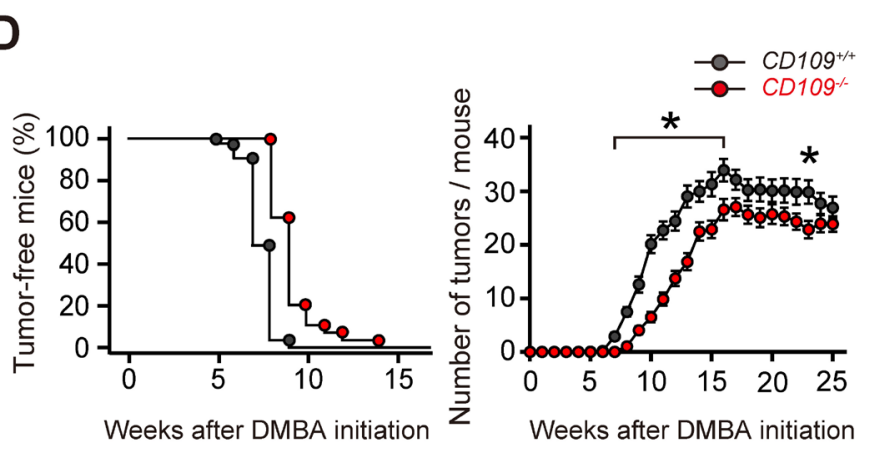

E

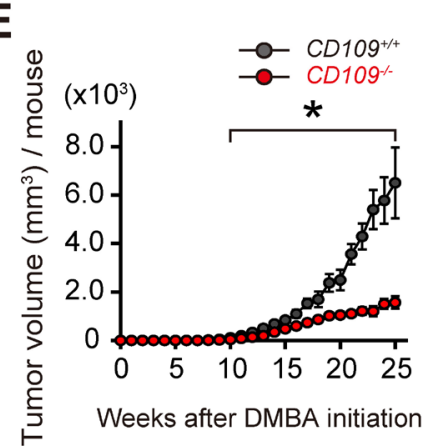

$\mathbf{F}$

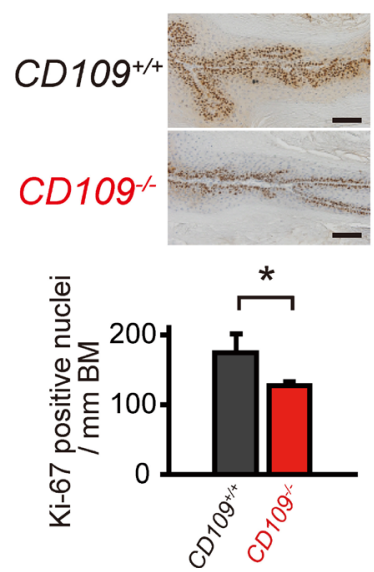

G

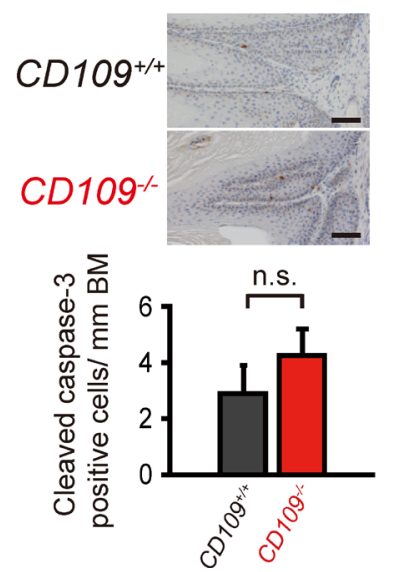

$\mathrm{H}$

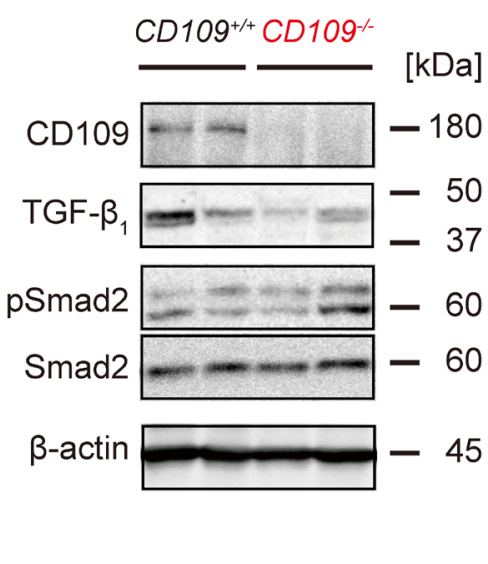

Figure 3: DMBA/TPA-induced skin tumorigenesis was suppressed in CD109 $^{-/-}$mice. A. Schematic diagram of the twostage chemical carcinogenesis protocol in mouse skin. B. Representative macroscopic images of $C D 109^{+/+}$and $C D 109^{-/-}$mice at 16 weeks after DMBA initiation. Scale bars, $1 \mathrm{~cm}$. C. Representative histological images of papillomas isolated from $C D 109^{+/+}$and $C D 109^{-/-}$ mice at 17 weeks after DMBA initiation. Scale bars, $500 \mu \mathrm{m}$. D. Percentage of tumor-free mice (left) and average number of tumors per mouse (right) during DMBA/TPA tumorigenesis (27 mice in the $C D 109^{+/+}$group and 22 mice in the CD109-/- group). E. Tumor volume was significantly decreased in $C D 109^{-/}$mice compared with in $C D 109^{+/+}$mice 10-25 weeks after DMBA initiation (n $=9$ per group). F, G. Immunohistochemical staining for Ki-67 (F) and cleaved caspase-3 (G) in $C D 109^{+/+}$and $C D 109^{-/-}$papillomas at 17 weeks after DMBA initiation (left). The numbers of positive cells in epidermis were counted per mm of basement membrane $(\mathrm{BM})($ right, $\mathrm{n}=6 \mathrm{per}$ group). Scale bars, $100 \mu \mathrm{m}$. H. Immunoblot analysis of $C D 109^{+/+}$and $C D 109^{-/-}$papilloma lysates prepared at 17 weeks after DMBA initiation, using antibodies against CD109, TGF- $\beta 1$, pSmad2, and Smad2. $\beta$-actin expression is shown as a loading control. TPA, 12-Otetradecanoylphorbol-13-acetate; n.s., not significant; $* P<0.05$. 
number of Ki-67-positive cells was significantly higher in papillomas of $C D 109^{+/+}$mice than in those of $C D 109^{-/-}$ mice at 17 weeks after DMBA initiation $(P<0.05$; Figure $3 \mathrm{~F}$, Supplementary Figure S5B). However, no significant difference in the number of cleaved caspase-3-positive cells was detected between the two mouse groups (Figure 3G, Supplementary Figure S5C).

To address the mechanism of increased resistance to DMBA/TPA-induced tumorigenesis in $C D 109^{-/-}$skin, lysates from the papillomas were subjected to immunoblot analysis using antibodies against TGF- $\beta 1$, phospho-Smad 2 and $\mathrm{Smad} 2$ (Figure 3H). The results show that there were no apparent changes in the levels of TGF- $\beta 1$ expression or Smad2 phosphorylation between $C D 109^{+/+}$and $C D 109^{-/-}$ papillomas.

We sacrificed the mice at 25 or 40 weeks after DMBA initiation and performed pathological analyses (Table 1, Supplementary Table S4). Our study did not show any correlation between CD109 deficiency and pathological features of invasive tumors (SCCs), such as malignant conversion rate, histological differentiation (Supplementary Figure S5D), invasion depth (Table 1, Supplementary Table S4) or number of metastatic lesions (Supplementary Figure S5E). These findings suggest that CD109 deficiency suppresses squamous cell papilloma formation in vivo, and that the chronic skin inflammation observed in $C D 109^{-1-}$ mice with increased $T g f b 1, C s f 2$, and $T n f a$ expression may reduce early-stage tumorigenesis, but not malignant conversion.

\section{DMBA/TPA-induced epidermal proliferation is suppressed in $\mathrm{CD}_{109^{-/-}}$mice}

We next compared the histological changes in dorsal skin before papilloma formation between $C D 109^{+/+}$and $C D 109^{-/-}$mice. Compared with that of $C D 109^{-/-}$mice, the skin of $C D 109^{+/+}$mice exhibited apparent thickening of the epidermis at 9 weeks after DMBA initiation (Figure 4A). We also performed immunohistochemical analysis using antibodies against TGF- $\beta 1$ and Nrf2. TGF- $\beta 1$ expression levels tended to be higher in $C D 109^{-/-}$skin than in $\mathrm{CD}_{109^{+/+}}$skin at each time point, but no significant differences were observed in Nrf2 staining at 5 or 9 weeks after DMBA initiation (Supplementary Figure S6).

\section{H-ras mutation induced by DMBA/TPA treatment is less frequent in $\mathrm{CD}_{109^{-/}}$skin than in $\mathrm{CD}_{109^{+/+}}$skin}

This finding prompted us to examine genetic changes before papilloma formation. Because H-ras ${ }^{(Q 61 L)}$ mutation was reportedly found before the appearance of papillomas [36], we assessed H-ras ${ }^{(Q 61 L)}$ gene mutation in skin using a mutation-specific PCR assay at 9 weeks after DMBA initiation. At this time point, no or few papillomas were observed in skin (Figure 3D). In this assay, less frequent mutation of the H-ras ${ }^{(Q 61 L)}$ gene was detected in genomic DNA from $C D 109^{-1-}$ skins compared with in that from $C D 109^{+/+}$skins (Figure 4B). We also investigated the effects of CD109 deficiency on epidermal proliferation with TPA treatment alone using a TPA-induced skin inflammation model (Supplementary Figure S7A); however, we identified no significant differences between $C D 109^{+/+}$and $C D 109^{-/-}$mice in epidermal thickness, the number of Ki-67-positive cells or inflammation-related gene expression levels (Supplementary Figure S7B-D). These results suggest that CD109 plays a role in the earlier phase of skin tumorigenesis, such as in DMBA-induced H-ras ${ }^{(Q 61 L)}$ mutation.

\section{CD109 deficiency decreases skin sensitivity to DMBA}

To investigate the role of CD109 in the skin response to DMBA, we performed immunohistochemical analysis of $\mathrm{CD}_{109^{+/+}}$and $C D 109^{-/-}$skins at $24 \mathrm{~h}$ after DMBA treatment (Figure 5). Although there was no significant difference in the number of $\mathrm{Ki}$-67-positive cells between $C D 109^{+/+}$and $C D 109^{-/-}$skins, the number of cells positive for phospho-p53 as a cellular stress marker [41], cleaved caspase-3 as an apoptosis marker, and phospho-H2AX as a DNA damage marker [42] were reduced in $C D 109^{-/}$skins compared with $C D 109^{+/+}$skins. These results suggest that CD109 deficiency decreases skin sensitivity to cellular stress including DNA damage by DMBA, resulting in less frequent mutation of the H-ras ${ }^{(Q 61 L)}$ gene.

\section{DISCUSSION}

We previously reported that CD109 is associated with human tumor development, especially in SCCs [12-14, 17, 20]. In this study, we therefore investigated the role of CD109 in skin tumorigenesis in vivo, using a two-stage carcinogenesis model in CD109-deficient mice. The number and size of papillomas were significantly decreased in $\mathrm{CD}_{109^{-/-}}$mice compared with in $\mathrm{CD}_{109^{+/+}}$ mice; however, we found no significant differences in malignant conversion rate, histological type or invasion/ metastasis between $C D 109^{+/+}$and $C D 109^{-/-}$tumors. Our data suggest that the chronic skin inflammation with TGF- $\beta$ protein expression in the dermis that is observed in $C D 109^{-/-}$mice reduces early-stage skin tumorigenesis, but does not influence malignant conversion. Although the mechanisms underlying the development and progression of the corresponding human skin disease remain elusive, CD109 deficiency may be a factor in the tumorsuppressing effects of chronic skin inflammation.

While CD109 is reported to function as a negative regulator of TGF- $\beta$ signaling in human keratinocytes [2225], we previously observed no effect of CD109 deficiency 
Table 1: Pathological analysis of skin tumors from $\mathrm{CD}_{109^{+/+}}$and $\mathrm{CD}_{109^{-/}}$mice at 25 weeks after DMBA initiation

\begin{tabular}{|c|c|c|c|}
\hline CD109 genotypes & $+/+$ & $-1-$ & $P$ value \\
\hline Number of mice & 9 & 9 & \\
\hline Total number of tumors & 258 & 193 & \\
\hline $\begin{array}{l}\text { Total number of invasive } \\
\text { tumors }\end{array}$ & 36 & 31 & \\
\hline Malignant conversion rate ${ }^{a}$ & $14.0 \%$ & $16.1 \%$ & 0.53 \\
\hline \multicolumn{4}{|l|}{ Primary skin lesions } \\
\hline Invasive tumor size $(\mu \mathrm{m})$ & $6.9 \pm 0.7$ & $5.8 \pm 0.5$ & 0.20 \\
\hline Differentiation & & & 0.57 \\
\hline \multicolumn{4}{|l|}{ Conventional SCCs ${ }^{\text {b) }}$} \\
\hline Well differentiated & $26(72 \%)$ & $20(65 \%)$ & \\
\hline Moderately differentiated & $6(17 \%)$ & $9(29 \%)$ & \\
\hline Poorly differentiated & $3(8 \%)$ & $1(3 \%)$ & \\
\hline Spindle cell carcinoma & $1(3 \%)$ & $1(3 \%)$ & \\
\hline Invasion depth & & & 0.43 \\
\hline Dermis & $32(89 \%)$ & $30(97 \%)$ & \\
\hline Hypodermis & $3(8 \%)$ & $1(3 \%)$ & \\
\hline Muscle & $1(3 \%)$ & $0(0 \%)$ & \\
\hline Metastatic lesions & $2 / 9(22 \%)$ & $0 / 9(0 \%)$ & 0.13 \\
\hline
\end{tabular}

a) Malignant conversion rate $=$ total number of invasive tumors/total number of tumors

b) SCCs, squamous cell carcinomas

on the TGF- $\beta$ signaling pathway in physiological and pathological conditions in vivo [27]. In this study, we showed that CD109 deficiency enhances TGF- $\beta$ / Smad signaling in whole skin, including dermis, and Nrf2 expression in the epidermis in skin tumorigenesis. Recently, Oshimori et al. [31] reported that the TGF- $\beta$ / p21/Nrf2 pathway plays an important role in antioxidant metabolism in skin SCC. TGF- $\beta$ was detected in skin stroma and Smad2 phosphorylation was enhanced in some skin stromal cells. The authors also detected Nrf2 and p21 expression in TGF- $\beta$-responding tumor cells at the tumorstromal interface [31]. In addition, Nrf2-deficient mice were reported to be more susceptible to DMBA-induced skin tumorigenesis [33] and Nrf2 activation protected keratinocytes in the early phase of skin tumorigenesis [34]. These results are consistent with our data, suggesting that CD109 deficiency increases DMBA metabolism via the TGF- $\beta / \mathrm{p} 21 / \mathrm{Nrf} 2$ pathway and resistance to DMBAinduced H-ras mutation in mouse keratinocytes.

Although we performed microarray analysis of the skin of DMBA-untreated or -treated $C D 109^{+/+}$and $C D 109^{-/-}$mice, we did not detect any changes to suggest possible mechanisms for the effects observed other than the TGF- $\beta / \mathrm{p} 21 / \mathrm{Nrf} 2$ pathway. However, it is interesting to note that altered expression of genes including Tpsab1, Shh, S100a7a and Il20, which are associated with tumorigenesis or psoriasis, was observed in the microarray analysis (Supplementary Tables S3 and S5). Altered expression of tryptase $\alpha 1$ and $\beta 1$, encoded by Tpsab1, has been reported to be associated with SCC; however, it is controversial whether they are increased or decreased in SCC $[43,44]$. Sonic hedgehog, encoded by $\mathrm{Shh}$, is well known to be involved in basal cell carcinoma formation [45], but to our knowledge, there have been no reports implicating Shh in SCC carcinogenesis. S100A15, encoded by $S 100 a 7 a$, and IL-20 are known to be upregulated in psoriatic skin $[46,47]$, which is similar to the phenotype of CD109-deficient mice [27].

Interestingly, we detected more TGF- $\beta$ protein in the dermis of $C D 109^{-/-}$mice than in that of $C D 109^{+/+}$ mice. While CD109 is known to negatively regulate TGF- $\beta$ signaling in human keratinocytes, probably by direct modulation of receptor activity [21-24], our finding implies that CD109 might also suppress TGF- $\beta$ signaling via reduction of TGF- $\beta$ in the dermis. Notably, we detected a strong TGF- $\beta$ signal in the epidermis-dermis junction 
in $C D 109^{-/-}$skin by immunohistochemistry using antiTGF- $\beta$ antibody, whereas TGF- $\beta$ was undetectable in the epidermis. This result suggests that the epidermal-dermal interaction, involving TGF- $\beta$ signaling, could contribute to the suppression of DMBA/TPA-induced epidermal proliferation in $C D 109^{-/-}$mice. Additionally, the finding that Smad2 phosphorylation levels were similar between $C D 109^{+/+}$and $C D 109^{-/-}$papillomas could result from the lower amount of stroma found in papillomas compared with in normal skin. One limitation of this study is that it does not address the mechanism underlying the increase in TGF- $\beta$ levels in $C D 109^{-/-}$dermis. Although speculative, it is interesting to consider that TGF- $\beta$ in $C D 109^{-/-}$dermis may result from increased secretion of TGF- $\beta$ by dermal stromal cells, such as fibroblasts or macrophages.

Although the epidermal thickness and BrdU-positive ratio (proliferation index) were significantly increased in the epidermis of $C D 109^{-/-}$mice compared with in that of $C D 109^{+/+}$mice without DMBA/TPA treatment in our previous study [27], the epidermal thickness and the number of Ki-67-positive cells was significantly decreased in DMBA/TPA-treated skin of $C D 109^{-1-}$ mice compared with in that of $\mathrm{CD}_{109^{+/+}}$mice in this study. This difference suggests that CD109 deficiency suppresses DMBA/TPA-induced epidermal hyperplasia or papilloma formation by a mechanism different from those

A

$C D 109^{+/+}$

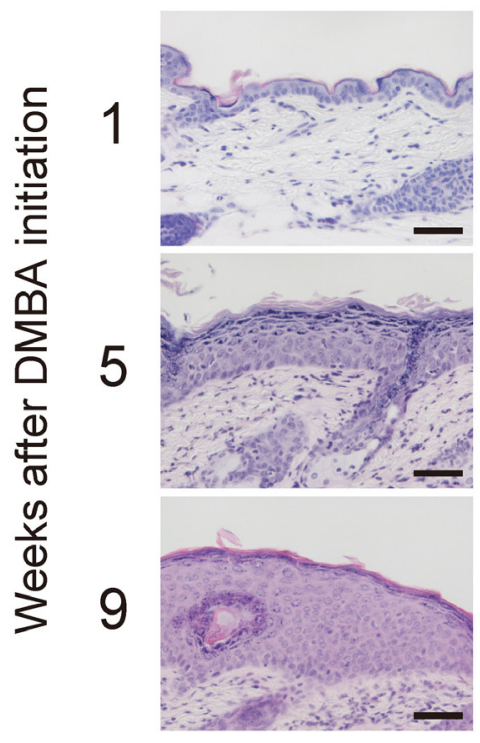

B

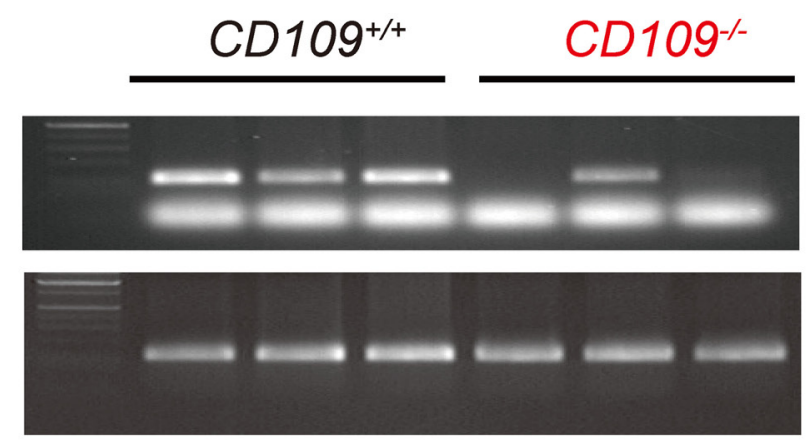

$C D 109^{-1-}$
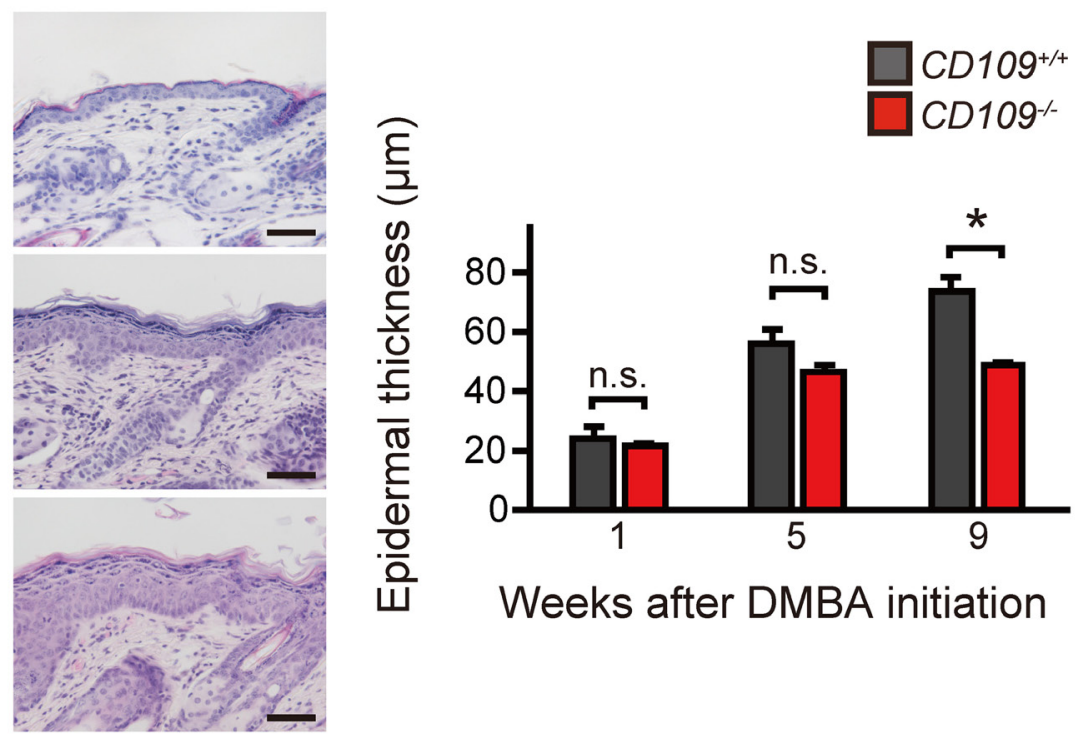

Figure 4: DMBA/TPA-induced proliferation of epidermal keratinocytes was suppressed in $C D 109^{-/-}$mice. A. Left, representative microscopic images of $\mathrm{CD}_{109^{+/+}}$and $\mathrm{CD}_{109^{-/}}$skins treated with DMBA alone (1 week after DMBA initiation) or DMBA and TPA (5 and 9 weeks after DMBA initiation). Right, quantification of epidermal thickness at indicated time points in $C D 109^{+/+}$and $C D 109^{-/-}$skins (n $=4$ per group). Scale bars, $50 \mu \mathrm{m}$. B. H-ras ${ }^{(Q 61 L)}$ mutation-specific PCR assay using genomic DNA from $C D 109^{+/+}$and $\mathrm{CD}_{109^{-/-}}$skins at 9 weeks after DMBA initiation (left). Right, quantification of signal intensity of mutant H-ras ${ }^{(661 L)}$ normalized to that of Gapdh ( $\mathrm{n}=3$ per group). n.s., not significant; $* P<0.05$. 
operating under physiological conditions as observed in our previous study. In addition, we previously reported that CD109 expression levels were significantly higher in well-differentiated SCCs of the oral cavity and in low-grade urothelial carcinomas of the urinary bladder than in moderately or poorly differentiated SCCs and in high-grade urothelial carcinomas, respectively $[17,19$, 20]. These results suggest that CD109 expression may be associated with tumor differentiation. However, we found no significant differences in the histological differentiation of carcinomas between $C D 109^{+/+}$and $C D 109^{-/-}$mice in the present study. Further investigation is necessary to clarify the role of CD109 in invasion, differentiation, and metastasis of skin cancer.

In conclusion, our findings suggest that CD109 deficiency plays a role in suppression of the mutation rate of the H-ras gene in the early phase of DMBA/TPAinduced skin tumorigenesis by enhancing the TGF- $\beta / \mathrm{p} 21 /$

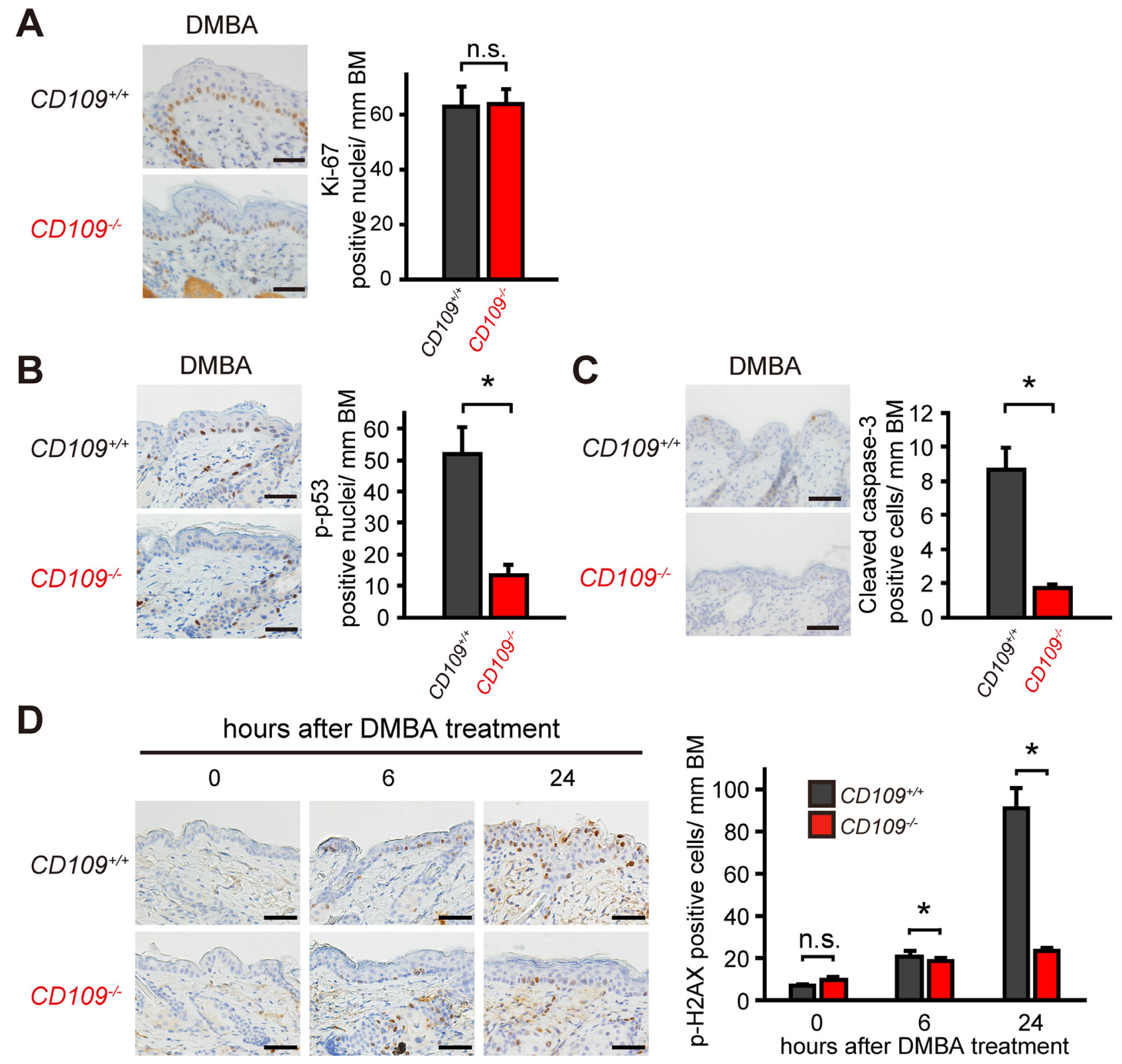

Figure 5: CD109 deficiency decreased skin sensitivity to DMBA. A-C. Immunohistochemical staining for Ki-67 (A), p-p53 (B), and cleaved caspase-3 (C) in $C D 109^{+/+}$and $C D 109^{-/-}$skins at $24 \mathrm{~h}$ after DMBA treatment (left panels). The numbers of positive cells in epidermis were counted per mm of basement membrane (BM) (right graphs; $\mathrm{n}=4$ per group). Scale bars, $100 \mu \mathrm{m}$. D. Immunohistochemical staining for p-H2AX in $\mathrm{CD}_{109^{+/+}}$and $C D 109^{-/-}$skins at 0,6 and $24 \mathrm{~h}$ after DMBA treatment (left panels). The number of p-H2AX-positive cells in epidermis was counted per mm of BM (right graph; $\mathrm{n}=4$ per group). Scale bars, $100 \mu \mathrm{m}$. n.s., not significant; $* P<0.05$. 
Nrf2 pathway, and significantly reduces the number and size of papillomas. Further analyses using different types of tumorigenesis models such as ultraviolet radiation would provide insights into the mechanism of the tumorsuppressing effects of CD109 associated with chronic inflammation.

\section{MATERIALS AND METHODS}

\section{Mice}

Wild-type FVB/N $\left(C D 109^{+/+}\right)$mice were purchased from CLEA Japan, Inc. (Tokyo, Japan). CD109 mice were generated as previously described [27] and backcrossed onto the FVB/N background for 10 generations. FVB/N mice display a high incidence of SCC after treatment with various tumor-induction protocols [48]. All mice were housed in the animal facilities of Nagoya University Graduate School of Medicine. All animal protocols were approved by the Animal Care and Use Committee of Nagoya University Graduate School of Medicine (approval ID number 27338).

\section{RNA isolation and real-time quantitative PCR (Q-PCR)}

Whole-skin samples were snap-frozen in liquid nitrogen and ground to a fine powder using Multi-Beads Shocker (Yasui Kikai Corporation, Osaka, Japan). Total RNA was isolated from cultured cells or tissue samples using TRIzol reagent (Invitrogen, Carlsbad, CA), treated with DNase I (Qiagen, Hilden, Germany) and further purified using an RNeasy Mini Kit (Qiagen) following the manufacturer's instructions. The concentration and purity of the extracted RNA were determined using a NanoDrop 2000 (Thermo Fisher Scientific, Wilmington, DE). At least two independent RNA extractions were performed for each sample. Total RNA (500 ng) was then reversetranscribed into cDNA using a ReverTra Ace qPCR RT Kit (Toyobo, Osaka, Japan). Q-PCR analysis was performed using an MX3005P system (Agilent Technologies, Santa Clara, CA, USA) with THUNDERBIRD SYBR qPCR Mix (Toyobo) following the manufacturer's instructions. All Q-PCR reactions were performed in duplicate and the results were analyzed using the comparative $\mathrm{Ct}$ method. The $\mathrm{Ct}$ values of samples and controls were normalized to those of Gapdh. All primer sets used in this study are shown in Supplementary Table S1.

\section{Immunohistochemistry}

Skin or tumor tissues were fixed for $24 \mathrm{~h}$ in $10 \%$ neutral-buffered formalin (Nacalai Tesque Inc., Kyoto, Japan), dehydrated, and embedded in paraffin. Sections (4- $\mu \mathrm{m}$ thick) were prepared for hematoxylin and eosin staining and immunohistochemistry. Sections were deparaffinized in xylene and rehydrated in a graded series of ethanol. For antigen retrieval, sections were immersed in Target Retrieval Solution pH 9 or pH 6 (Dako, Hamburg, Germany), and incubated for $40 \mathrm{~min}$ at $100{ }^{\circ} \mathrm{C}$ in a water bath or heated for $15 \mathrm{~min}$ at $121{ }^{\circ} \mathrm{C}$ by autoclaving. Non-specific binding was blocked with Protein Block Serum-Free (Dako) for $30 \mathrm{~min}$ at room temperature (RT). Sections were incubated with primary antibodies diluted in $1 \% \mathrm{BSA} / \mathrm{PBS}$ overnight at $4{ }^{\circ} \mathrm{C}$. The primary antibodies used in this study were: rabbit polyclonal anti-TGF- $\beta 1$ (V) antibody (Santa Cruz Biotechnology, Santa Cruz, CA), rat monoclonal anti-F4/80 (BM8) antibody (eBioscience, San Diego, CA), rabbit polyclonal anti-Nrf2 (H-300) antibody (Santa Cruz Biotechnology), rabbit polyclonal anti-keratin 14 (Poly19053) antibody (BioLegend, San Diego, CA), rat monoclonal anti-mouse Ki-67 (TEC-3) antibody (Dako), rabbit monoclonal anti-cleaved caspase-3 (5A1E) antibody (Cell Signaling Technology, Danvers, MA), rabbit monoclonal anti-phospho-p53 (Ser15) (D4S1H) antibody (Cell Signaling Technology), and mouse monoclonal anti-phospho-histone H2AX (Ser139) (JBW301) antibody (EMD Millipore, Billerica, MA). Endogenous peroxidase was inhibited with $0.3 \%$ hydrogen peroxide in methanol for $15 \mathrm{~min}$. The sections were incubated with the secondary antibodies EnVision+ System-HRP Labeled Polymer Anti-Rabbit or Anti-Mouse (Dako), or N-Histofine Simple Stain Mouse MAX PO (Rat) (Nichirei Bioscience, Tokyo, Japan) for $30 \mathrm{~min}$ at RT except for the sections incubated with anti-Ki-67 antibody, which were incubated with biotinylated secondary antibody followed by incubation with peroxidase-conjugated streptavidin (Nichirei Bioscience). Signals were visualized by the Liquid DAB + Substrate-Chromogen System (Dako) with nuclear counterstaining using hematoxylin. To quantify the immunohistochemical staining in mouse epidermis, cells stained positive for each protein of interest were counted per field (dermis) or per length of basement membrane (BM).

\section{Western blot analysis}

Skin or tumor samples were snap-frozen in liquid nitrogen, ground to a fine powder by Multi-Beads Shocker (Yasui Kikai, Inc.), lysed in SDS sample buffer and prepared as previously described [27]. Protein samples (30 $\mu \mathrm{g})$ were subjected to SDS-polyacrylamide gel electrophoresis, and immunoblot analysis was performed as previously described [27]. The antibodies used in this study were: rabbit polyclonal anti-TGF- $\beta 1$ (V) antibody (Santa Cruz Biotechnology), rabbit monoclonal antiphospho-Smad2 (Ser465/467) (138D4) antibody (Cell Signaling Technology), rabbit monoclonal anti-Smad2 (D43B4) antibody (Cell Signaling Technology) and mouse monoclonal anti- $\beta$-actin (AC-74) antibody (SigmaAldrich, Saint Louis, MO). To confirm equal loading, membranes were reprobed with anti- $\beta$-actin antibody. 


\section{Isolation and short-term culture of primary mouse keratinocytes}

Dorsal skin was obtained from newborn mice and immersed in Dispase II solution, $2.5 \mathrm{U} / \mathrm{ml}$ Dispase II (Roche, Indianapolis, IN) with antibiotic-antimycotic solution CnT-ABM10 (CELLnTEC, Bern, Switzerland) in CnT-PR medium (CELLnTEC) for $16 \mathrm{~h}$ at $4{ }^{\circ} \mathrm{C}$. After being washed with PBS, the sheet of epidermis, separated from the dermis, was floated on a $500 \mu$ drop of TrypLE select (Thermo Fisher Scientific) for $25 \mathrm{~min}$ at RT. After addition of $2 \mathrm{ml}$ of medium to the drop, the sheet of epidermis was shaken gently on the drop to disperse the keratinocytes. The cell suspension was collected in a 15-ml tube containing fetal bovine serum (FBS). The cells were filtered through a $70-\mu \mathrm{m}$ cell strainer to remove clumps and debris, centrifuged for $7 \mathrm{~min}$ at 200 $\times g$, suspended in medium with $10 \%$ FBS and centrifuged again for $7 \mathrm{~min}$ at $1300 \mathrm{rpm}$. The cells were plated in CnT-PR medium with $10 \%$ FBS at $1.5 \times 10^{5}$ cells $/ \mathrm{cm}^{2}$ and incubated at $37{ }^{\circ} \mathrm{C}$ in a humidified $5 \% \mathrm{CO}_{2}$ incubator. The medium was removed $16 \mathrm{~h}$ after plating and replaced with CnT-PR medium without FBS. The medium was changed every other day.

\section{Cell proliferation and cytotoxic assay}

Cell proliferation was measured by water-soluble tetrazolium (WST)-1 assay (Roche). Mouse keratinocytes were cultured at a density of $5.0 \times 10^{4}$ cells/well in a 96well microplate. At $0,1,2$, and 4 days after seeding, the WST-1 reagent was added to the cultures and cells were incubated for $4 \mathrm{~h}$. For cytotoxic assay, the cells were seeded at a density of $3.0 \times 10^{5}$ cells/well in a 24 -well microplate and incubated for $24 \mathrm{~h}$. The cells were exposed for $24 \mathrm{~h}$ to DMBA (Sigma-Aldrich) or dimethyl sulfoxide (DMSO, Wako, Osaka, Japan) as a control, or exposed for 48 h to cisplatin (CDDP, Bristol-Myers Squibb, New York, NY) or PBS as a control. WST-1 reagents were added to the cultures and cells were incubated for $4 \mathrm{~h}$ before absorbance measurement. Absorbance at $450 \mathrm{~nm}$ and 650 nm was measured using a microplate reader, Powerscan 4 (DS Pharma Biomedical, Osaka, Japan). The measured absorbance (A450-A650) is directly proportional to the number of living cells. Note that the cells were pretreated with $10 \mathrm{ng} / \mathrm{ml}$ TGF- $\beta 1$ (R\&D Systems, Minneapolis, $\mathrm{MN}$ ), $10 \mathrm{ng} / \mathrm{ml}$ SB431542 (TGFBRI inhibitor, Selleck Chemicals, Houston, TX) or PBS as a control for $24 \mathrm{~h}$ before incubation with DMBA.

\section{Immunofluorescence analysis}

Keratinocytes isolated from newborn mice were grown in 3.5-cm glass-based dishes, washed with PBS and fixed with 4\% paraformaldehyde for $15 \mathrm{~min}$ at RT. After washing with PBS, $0.3 \%$ Triton X-100 (Wako) in PBS was applied for 3 min at RT. The cells were blocked using 3\% skim milk in PBS for 30 min and incubated for $1 \mathrm{~h}$ at RT with appropriate primary antibodies. The primary antibodies used in this study were: rabbit monoclonal anti-phospho-Smad2 (Ser465/467) (138D4) (Cell Signaling Technology), rat monoclonal anti-p21 [HUGO291] (Abcam, Cambridge, UK) and rabbit polyclonal anti-Nrf2 (H-300) (Santa Cruz Biotechnology). The cells were washed with PBS and incubated for 30 min at RT in PBS containing Alexa Fluor 488 and/or 555-conjugated secondary antibodies (Life Technologies, Carlsbad, CA) with nuclear counterstaining using DAPI. Immunofluorescence was detected with a confocal laserscanning microscope (LSM 700, Carl Zeiss, Oberkochen, Germany). To analyze fluorescence intensity, $C D 109^{+/+}$ and $\mathrm{CD}_{109^{-/}}$keratinocytes were immunostained at the same time and under the same conditions. The "Histogram" function of ZEN software (Carl Zeiss) was used to detect the fluorescence intensity per cell as follows: the fluorescence intensity for individual cells in the green or red channels was measured for the area inside the nuclei only, by masking the area outside the nuclei using the blue channel (DAPI). The average measurements, normalized to DAPI fluorescence intensity, were used to compare fluorescence intensity between $C D 109^{+/+}$and $C D 109^{-/-}$ cells.

\section{Skin tumorigenesis assay}

Murine skin tumors were induced by a standard two-stage chemical carcinogenesis protocol as previously described [49, 50]. In brief, 6-8-week-old female mice were shaved on the dorsal skin with electric clippers and received a single topical application of $100 \mathrm{nmol}$ DMBA (Sigma-Aldrich) in $200 \mu \mathrm{l}$ acetone $24 \mathrm{~h}$ after shaving. One week after DMBA treatment, the mice received topical applications of $5 \mathrm{nmol}$ TPA (Sigma-Aldrich) in $200 \mu \mathrm{l}$ acetone twice weekly for 15 weeks. Mice were assessed on weekly basis for a period of up to 25 or 35 weeks after DMBA treatment. The appearance of skin tumors was recorded once a week. All animal protocols were approved by the Animal Care and Use Committee of Nagoya University Graduate School of Medicine (Approval ID number: 27338).

\section{Analysis of H-ras mutations in codon 61}

Genomic DNA was isolated from snap-frozen DMBA/TPA-treated skin using a NucleoSpin Tissue kit (Macherey-Nagel, Düren, Germany) following the manufacturer's instruction. The concentration and purity of the extracted genomic DNA were determined using a NanoDrop 2000 (Thermo Fisher Scientific). Mutation of H-ras in codon 61 was detected by mutation-specific PCR assay [36]. The primers for mutant H-ras ${ }^{(261 L)}$ were as follows: forward primer, 5'-CTA AGC CTG TTG TTT TGC AGG AC-3' and reverse primer, 5'-CAT GGC ACT 
ATA CTC TTC TA-3'. Before amplification, genomic DNA samples were denatured for $5 \mathrm{~min}$ at $95{ }^{\circ} \mathrm{C}$. Each amplification cycle consisted of denaturation for $30 \mathrm{sec}$ at $95^{\circ} \mathrm{C}$, hybridization for $20 \mathrm{sec}$ at $58{ }^{\circ} \mathrm{C}$, and elongation for $20 \mathrm{sec}$ at $78{ }^{\circ} \mathrm{C}$. After 40 cycles of amplification, 5 $\mu \mathrm{l}$ of PCR products were analyzed by $1.5 \%$ agarose gel electrophoresis and ethidium bromide staining.

\section{Statistical analysis}

Statistical analyses were performed using IBM SPSS software 22.0 (IBM, Armonk, NY). Numerical results are presented as mean value \pm standard deviation (S.D.) or standard error of the mean (S.E.M.), or in box and whisker plots. For comparison of the differences between two groups, a two-tailed Student's t test, MannWhitney $U$ test or one-way analysis of variance (ANOVA) was performed. Two-way ANOVA was used to evaluate differences to compare four groups. For tumor-free analysis, Kaplan-Meier log-rank analysis was performed. Clinicopathological features were evaluated with $\chi^{2}$ tests. A P value of $<0.05$ was considered statistically significant.

\section{ACKNOWLEDGMENTS}

We thank Mrs. Kaori Ushida, Mr. Kozo Uchiyama and Mrs. Kayoko Endo (Department of Pathology), and Dr. Tamio Ohno and Dr. Koji Nomaru (Division for Research of Laboratory Animals, Center for Research of Laboratory Animals and Medical Research Engineering) for technical assistance, and gratefully acknowledge Dr. Motoyoshi Endo (Kumamoto University) for information on DMBA and TPA.

\section{CONFLICTS OF INTEREST}

The authors declare no conflicts of interest.

\section{FINANCIAL SUPPORT}

This work was supported by a Grant-in-Aid for Scientific Research (S) (JSPS KAKENHI Grant Number 26221304; M. Takahashi) and a Grant-in-Aid for Young Scientists (B) (JSPS KAKENHI Grant Number 25860293; S. Mii) from the Japan Society for the Promotion of Science.

\section{REFERENCES}

1. Karia PS, Han J, Schmults CD. Cutaneous squamous cell carcinoma: estimated incidence of disease, nodal metastasis, and deaths from disease in the United States, 2012. J Am Acad Dermatol. 2013; 68:957-966.

2. Lallas A, Pyne J, Kyrgidis A, Andreani S, Argenziano G, Cavaller A, Giacomel J, Longo C, Malvestiti A, Moscarella E, Piana S, Specchio F, Hofmann-Wellenhof
$\mathrm{R}$, et al. The clinical and dermoscopic features of invasive cutaneous squamous cell carcinoma depend on the histopathological grade of differentiation. Br J Dermatol. 2015; 172:1308-1315.

3. Luch A. Nature and nurture - lessons from chemical carcinogenesis. Nat Rev Cancer. 2005; 5:113-125.

4. Briso EM, Guinea-Viniegra J, Bakiri L, Rogon Z, Petzelbauer P, Eils R, Wolf R, Rincon M, Angel P, Wagner EF. Inflammation-mediated skin tumorigenesis induced by epidermal c-Fos. Genes Dev. 2013; 27:1959-1973.

5. Sutherland DR, Yeo E, Ryan A, Mills GB, Bailey D, Baker MA. Identification of a cell-surface antigen associated with activated T lymphoblasts and activated platelets. Blood. 1991; 77:84-93.

6. Haregewoin A, Solomon K, Hom RC, Soman G, Bergelson JM, Bhan AK, Finberg RW. Cellular expression of a GPIlinked T cell activation protein. Cell Immunol. 1994; 156:357-370.

7. Smith JW, Hayward CP, Horsewood P, Warkentin TE, Denomme GA, Kelton JG. Characterization and localization of the Gova/b alloantigens to the glycosylphosphatidylinositol-anchored protein CDw109 on human platelets. Blood. 1995; 86:2807-2814.

8. Lin M, Sutherland DR, Horsfall W, Totty N, Yeo E, Nayar $\mathrm{R}, \mathrm{Wu}$ XF, Schuh AC. Cell surface antigen CD109 is a novel member of the $\alpha_{2}$ macroglobulin/C3, C4, C5 family of thioester-containing proteins. Blood. 2002; 99:1683-1691.

9. Kelton JG, Smith JW, Horsewood P, Humbert JR, Hayward CP, Warkentin TE. Gov ${ }^{a / b}$ alloantigen system on human platelets. Blood. 1990; 75:2172-2176.

10. Murray LJ, Bruno E, Uchida N, Hoffman R, Nayar R, Yeo EL, Schuh AC, Sutherland DR. CD109 is expressed on a subpopulation of $\mathrm{CD}_{3} 4^{+}$cells enriched in hematopoietic stem and progenitor cells. Exp Hematol. 1999; 27:1282-1294.

11. Giesert C, Marxer A, Sutherland DR, Schuh AC, Kanz L, Buhring HJ. Antibody W7C5 defines a CD109 epitope expressed on $\mathrm{CD}^{+} 4^{+}$and $\mathrm{CD} 34^{-}$hematopoietic and mesenchymal stem cell subsets. Ann N Y Acad Sci. 2003; 996:227-230.

12. Hashimoto $M$, Ichihara $M$, Watanabe $T$, Kawai $K$, Koshikawa K, Yuasa N, Takahashi T, Yatabe Y, Murakumo Y, Zhang JM, Nimura Y, Takahashi M. Expression of CD109 in human cancer. Oncogene. 2004; 23:3716-3720.

13. Zhang JM, Hashimoto M, Kawai K, Murakumo Y, Sato T, Ichihara M, Nakamura S, Takahashi M. CD109 expression in squamous cell carcinoma of the uterine cervix. Pathol Int. 2005; 55:165-169.

14. Sato T, Murakumo Y, Hagiwara S, Jijiwa M, Suzuki C, Yatabe Y, Takahashi M. High-level expression of CD109 is frequently detected in lung squamous cell carcinomas. Pathol Int. 2007; 57:719-724.

15. Hasegawa M, Hagiwara S, Sato T, Jijiwa M, Murakumo Y, Maeda M, Moritani S, Ichihara S, Takahashi M. CD109, a 
new marker for myoepithelial cells of mammary, salivary, and lacrimal glands and prostate basal cells. Pathol Int. 2007; 57:245-250.

16. Hasegawa M, Moritani S, Murakumo Y, Sato T, Hagiwara S, Suzuki C, Mii S, Jijiwa M, Enomoto A, Asai N, Ichihara S, Takahashi M. CD109 expression in basal-like breast carcinoma. Pathol Int. 2008; 58:288-294.

17. Hagiwara S, Murakumo Y, Sato T, Shigetomi T, Mitsudo $\mathrm{K}$, Tohnai I, Ueda M, Takahashi M. Up-regulation of CD109 expression is associated with carcinogenesis of the squamous epithelium of the oral cavity. Cancer Sci. 2008; 99:1916-1923.

18. Ohshima Y, Yajima I, Kumasaka MY, Yanagishita T, Watanabe D, Takahashi M, Inoue Y, Ihn H, Matsumoto Y, Kato M. CD109 expression levels in malignant melanoma. J Dermatol Sci. 2010; 57:140-142.

19. Hagikura M, Murakumo $Y$, Hasegawa M, Jijiwa M, Hagiwara S, Mii S, Hagikura S, Matsukawa Y, Yoshino Y, Hattori R, Wakai K, Nakamura S, Gotoh M, et al. Correlation of pathological grade and tumor stage of urothelial carcinomas with CD109 expression. Pathol Int. 2010; 60:735-743.

20. Hagiwara S, Yamamoto $N$, Furue $H$, Sakakura $H$, Shigetomi T, Murakumo Y, Hibi H, Takahashi M, Ueda M. Pathological analysis of Ki-67 and CD109 expression in tongue squamous cell carcinoma. J Oral Maxillofac Surg Med Pathol. 2013; 25:276-281.

21. Tam BY, Germain L, Philip A. TGF- $\beta$ receptor expression on human keratinocytes: a $150 \mathrm{kDa}$ GPI-anchored TGF- $\beta 1$ binding protein forms a heteromeric complex with type I and type II receptors. J Cell Biochem. 1998; 70:573-586.

22. Finnson KW, Tam BY, Liu K, Marcoux A, Lepage P, Roy S, Bizet AA, Philip A. Identification of CD109 as part of the TGF- $\beta$ receptor system in human keratinocytes. FASEB J. 2006; 20:1525-1527.

23. Hagiwara S, Murakumo Y, Mii S, Shigetomi T, Yamamoto N, Furue H, Ueda M, Takahashi M. Processing of CD109 by furin and its role in the regulation of TGF- $\beta$ signaling. Oncogene. 2010; 29:2181-2191.

24. Bizet AA, Liu K, Tran-Khanh N, Saksena A, Vorstenbosch J, Finnson KW, Buschmann MD, Philip A. The TGF- $\beta$ co-receptor, $\mathrm{CD} 109$, promotes internalization and degradation of TGF- $\beta$ receptors. Biochim Biophys Acta. 2011; 1813:742-753.

25. Litvinov IV, Bizet AA, Binamer Y, Jones DA, Sasseville D, Philip A. CD109 release from the cell surface in human keratinocytes regulates TGF- $\beta$ receptor expression, TGF- $\beta$ signalling and STAT3 activation: relevance to psoriasis. Exp Dermatol. 2011; 20:627-632.

26. Liu XX, Feng AP, He YM, Li Y, Wu Y, Lian X, Hu F, Li JW, Tu YT, Chen SJ. Association of down-regulation of CD109 expression with up-expression of Smad7 in pathogenesis of psoriasis. J Huazhong Univ Sci Technolog Med Sci. 2016; 36:132-136.
27. Mii S, Murakumo Y, Asai N, Jijiwa M, Hagiwara S, Kato T, Asai M, Enomoto A, Ushida K, Sobue S, Ichihara M, Takahashi M. Epidermal hyperplasia and appendage abnormalities in mice lacking CD109. Am J Pathol. 2012; 181:1180-1189.

28. Massagué J. TGF $\beta$ in Cancer. Cell. 2008; 134:215-230.

29. Massagué J. TGF $\beta$ signalling in context. Nat Rev Mol Cell Biol. 2012; 13:616-630.

30. Cui W, Fowlis DJ, Bryson S, Duffie E, Ireland H, Balmain A, Akhurst RJ. TGF $\beta 1$ inhibits the formation of benign skin tumors, but enhances progression to invasive spindle carcinomas in transgenic mice. Cell. 1996; 86:531-542.

31. Oshimori N, Oristian D, Fuchs E. TGF- $\beta$ promotes heterogeneity and drug resistance in squamous cell carcinoma. Cell. 2015; 160:963-976.

32. Chen W, Sun Z, Wang XJ, Jiang T, Huang Z, Fang D, Zhang DD. Direct interaction between Nrf2 and p21 Cip1/WAF1 upregulates the Nrf2-mediated antioxidant response. Mol Cell. 2009; 34:663-673.

33. Xu C, Huang MT, Shen G, Yuan X, Lin W, Khor TO, Conney AH, Kong AN. Inhibition of 7, 12-dimethylbenz(a) anthracene-induced skin tumorigenesis in C57BL/6 mice by sulforaphane is mediated by nuclear factor E2-related factor 2. Cancer Res. 2006; 66:8293-8296.

34. Rolfs F, Huber M, Kuehne A, Kramer S, Haertel E, Muzumdar S, Wagner J, Tanner Y, Bohm F, Smola $\mathrm{S}$, Zamboni N, Levesque MP, Dummer R, et al. Nrf2 Activation Promotes Keratinocyte Survival during Early Skin Carcinogenesis via Metabolic Alterations. Cancer Res. 2015; 75:4817-4829.

35. Nassar D, Latil M, Boeckx B, Lambrechts D, Blanpain C. Genomic landscape of carcinogen-induced and genetically induced mouse skin squamous cell carcinoma. Nat Med. 2015; 21:946-954.

36. Nelson MA, Futscher BW, Kinsella T, Wymer J, Bowden GT. Detection of mutant Ha-ras genes in chemically initiated mouse skin epidermis before the development of benign tumors. Proc Natl Acad Sci USA. 1992; 89:6398-6402.

37. Martinez FO, Gordon S. The M1 and M2 paradigm of macrophage activation: time for reassessment. F1000Prime Rep. 2014; 6:13.

38. Muqbil I, Banu N. Enhancement of pro-oxidant effect of 7, 12-dimethylbenz (a) anthracene (DMBA) in rats by preexposure to restraint stress. Cancer Lett. 2006; 240:213-220.

39. Schafer M, Werner S. Nrf2-A regulator of keratinocyte redox signaling. Free Radic Biol Med. 2015; 88:243-252.

40. Wu KC, Cui JY, Klaassen CD. Effect of graded Nrf2 activation on phase-I and -II drug metabolizing enzymes and transporters in mouse liver. PLoS One. 2012;7:e39006.

41. Carvajal LA, Manfredi JJ. Another fork in the road-life or death decisions by the tumour suppressor p53. EMBO Rep. $2013 ; 14: 414-421$. 
42. Rogakou EP, Pilch DR, Orr AH, Ivanova VS, Bonner WM. DNA double-stranded breaks induce histone H2AX phosphorylation on serine 139. J Biol Chem. 1998; 273:5858-5868.

43. Iamaroon A, Pongsiriwet S, Jittidecharaks S, Pattanaporn K, Prapayasatok S, Wanachantararak S. Increase of mast cells and tumor angiogenesis in oral squamous cell carcinoma. $\mathrm{J}$ Oral Pathol Med. 2003; 32:195-199.

44. Oliveira-Neto $\mathrm{HH}$, Leite AF, Costa NL, Alencar RC, Lara VS, Silva TA, Leles CR, Mendonca FE, Batista AC. Decrease in mast cells in oral squamous cell carcinoma: possible failure in the migration of these cells. Oral Oncol. 2007; 43:484-490.

45. Oro AE, Higgins KM, Hu Z, Bonifas JM, Epstein EH Jr, Scott MP. Basal cell carcinomas in mice overexpressing sonic hedgehog. Science. 1997; 276:817-821.

46. Sa SM, Valdez PA, Wu J, Jung K, Zhong F, Hall L, Kasman I, Winer J, Modrusan Z, Danilenko DM, Ouyang W. The effects of IL-20 subfamily cytokines on reconstituted human epidermis suggest potential roles in cutaneous innate defense and pathogenic adaptive immunity in psoriasis. $\mathrm{J}$ Immunol. 2007; 178:2229-2240.
47. Wolf R, Howard OM, Dong HF, Voscopoulos C, Boeshans K, Winston J, Divi R, Gunsior M, Goldsmith P, Ahvazi B, Chavakis T, Oppenheim JJ, Yuspa SH. Chemotactic activity of S100A7 (Psoriasin) is mediated by the receptor for advanced glycation end products and potentiates inflammation with highly homologous but functionally distinct S100A15. J Immunol. 2008; 181:1499-1506.

48. Hennings H, Glick AB, Lowry DT, Krsmanovic LS, Sly LM, Yuspa SH. FVB/N mice: an inbred strain sensitive to the chemical induction of squamous cell carcinomas in the skin. Carcinogenesis. 1993; 14:2353-2358.

49. Abel EL, Angel JM, Kiguchi K, DiGiovanni J. Multi-stage chemical carcinogenesis in mouse skin: fundamentals and applications. Nat Protoc. 2009; 4:1350-1362.

50. Aoi J, Endo M, Kadomatsu T, Miyata K, Ogata A, Horiguchi H, Odagiri H, Masuda T, Fukushima S, Jinnin M, Hirakawa S, Sawa T, Akaike T, et al. Angiopoietin-like protein 2 accelerates carcinogenesis by activating chronic inflammation and oxidative stress. Mol Cancer Res. 2014; 12:239-249. 